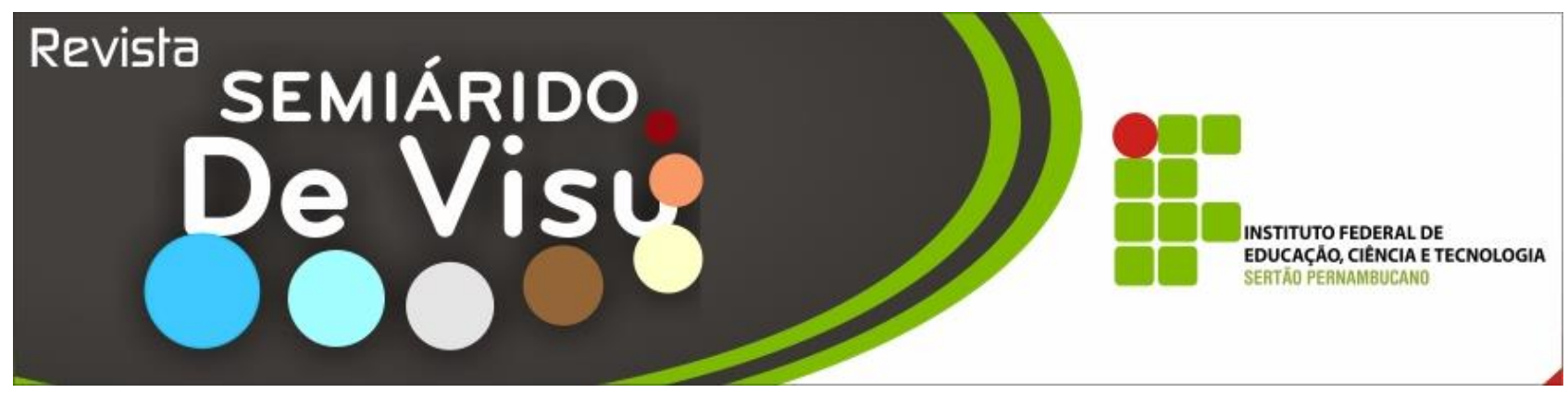

\title{
Montagem de painel educacional inovador para práticas de instalações elétricas
}

\author{
Edilane Cristina dos Santos Ribeiro ${ }^{1}$, Michelle da Silva Matias², Maria Alice de Freitas Marques ${ }^{3}$ \\ 1,2,3 Instituto Federal do Sertão Pernambucano- Campus Salgueiro, IFSPE, Rodovia BR 232, CEP 56.000-000. E-mail: \\ edilane19@hotmail.com¹, michelymatyas@gmail.com², alice.freitas@ifsertao-pe.edu.br ${ }^{3}$
}

\begin{abstract}
RESUMO: Em virtude do desenvolvimento econômico da cidade de Salgueiro no Sertão Pernambucano e, consequentemente, com a alta demanda de serviços especializados, os cursos técnicos oferecidos pelo IF Sertão- PE, em específico da área de edificações, surgem como uma solução para atender a necessidade de profissionais capacitados para atuarem dentro do mercado de trabalho local. Entretanto, a formação técnica desses profissionais na referida instituição enfrenta algumas dificuldades por conta da falta de recursos e laboratórios melhores equipados para que se possa melhor qualificar o público em questão. Portanto, visando colaborar em alternativas para aprimorar e romper com esse atual cenário no campus, além de aliar ensino e pesquisa, o presente trabalho teve como objetivo pesquisar e montar um painel educacional inovador, devido as suas características específicas no que diz respeito às atividades profissionais de instalações elétricas da região, para as tais aulas práticas. Com a concretização do projeto, o painel foi disponibilizado aos alunos do curso de edificações para testes em sala de aula, sendo realizada uma pesquisa qualiquantitativa com os envolvidos sobre os benefícios do uso do painel.
\end{abstract}

Palavras-chaves: instalações, elétricas, pesquisas, painel.

\section{Innovative educational painelmount for electrical installations practices}

\begin{abstract}
Due to the economic development of the city of Salgueiro in Sertão Pernambucano and, consequently, with the high demand for specialized services, the technical courses offered by IF Sertão-PE, specifically in the area of buildings, appear as a solution to meet the need of Trained professionals to work within the local labor market. However, the technical training of these professionals in this institution faces some difficulties due to the lack of resources and better equipped laboratories to better qualify the public in question. Therefore, in order to collaborate on alternatives to improve and break with this current scenario on campus, in addition to allying teaching and research, the present work aimed to research and set up an innovative educational panel, due to its specific characteristics with regard to professional activities Of electrical installations in the region, for such practical classes. With the realization of the project, the panel was made available to students of the building course for classroom tests, and a qualitative research was conducted with those involved on the benefits of using the panel.
\end{abstract}

Key words: electrical, installations, research, panel. 


\section{Introdução}

$\mathrm{I}$ nstalações elétricas prediais são parte de um conteúdo necessário para formação do técnico em edificações, o qual atuará ativamente em obras e construções dentro do mercado de trabalho. A cidade de Salgueiro em seu recente desenvolvimento econômico exibe uma frequente demanda de profissionais que atuem na área de edificações e consequentemente em instalações elétricas. Um projeto de instalações elétricas deve ser atendido e executado por profissionais da área e seguindo os conceitos estabelecidos na NBR 5410, "esta Norma estabelece as condições a que devem satisfazer as instalações elétricas de baixa tensão, a fim de garantir a segurança de pessoas e animais, o funcionamento adequado da instalação e a conservação dos bens". Assim sendo, o técnico que atuará nessa área deve ser bem qualificado, para garantir a segurança da instalação e destacar-se no mercado de trabalho por meio de seu aprendizado formação e é compromisso da instituição formante que o privilegie, aperfeiçoando seus métodos, a fim de capacitar seus futuros profissionais.

O Instituto Federal de Educação, Ciência e Tecnologia do sertão pernambucano campus Salgueiro situa-se como um exemplo do dito anteriormente:

Surge à necessidade de gerar mão-de-obra
especializada com formação científica,
tecnológica e humanística. [...] os profissionais
da área de Edificações do Instituto Federal de
Educação, Ciência e Tecnologia do Sertão
Pernambucano - Campus Salgueiro entende
que este é o desafio atual e futuro para a
formação de técnicos competentes para o
desempenho teórico-prático e para o
gerenciamento dos processos construtivos
(PCC, 2011).

Para melhorar o desenvolvimento do aluno uma alternativa é ampliar os métodos de ensino, consequentemente, preparando profissionais de qualidade para as empresas. Aulas práticas atendem a essa formação com qualidade, devido a suas pretensas simulações de situações reais dentro do mercado de trabalho. O IFSPE - Campus Salgueiro sofre de um déficit de aulas práticas de qualidade, por falta de recursos na instituição que contemplem algumas destas aulas, seja na falta de laboratórios e equipamentos, em especial na área de instalações elétricas.

A partir de pesquisas bibliográficas em plataformas virtuais de empresas no ramo de equipamentos e componentes elétricos, bem como pesquisas em campo na cidade de Salgueiro em empresas que atuam no ramo de instalações elétricas, foram colhidos dados para elaboração da escolha e opções de quais componentes e recursos seriam necessários e inovadores ao painel, agregando inovação para formação dos usuários.

Visitas em obras de construção na cidade de Salgueiro e região foram realizadas a fim de analisar possíveis erros e acertos, no que diz respeito à execução e atividades dentro da NRB 5410, e em como estão sendo executadas as instalações elétricas pelos profissionais que aqui atuam, auxiliando também para a base do funcionamento do painel e o que seria necessário para as aulas práticas e que estas assim cumpram seu papel na formação do profissional egresso e este ao atuar no mercado de trabalho possa realizar suas atividades no ramo e instalações elétricas de forma, segura, inovadora e principalmente que atenda os critérios regulamentadores.

\section{Material e métodos}

A metodologia constou com pesquisas em plataformas online acerca de empresas na área de instalações elétricas de renome nacional e regional, bem como equipamentos utilizados na área para auxílio na análise para montagem do painel, o objetivo dessa pesquisa em empresas nesta área, é agregar a montagem do painel, o conhecimento de atividades que são realizadas por profissionais de instalações. Podendo assim ser possível verificar os componentes necessários à instalação elétrica e possíveis inovações existentes na área, e se estes assim podem ser encontrados na cidade de Salgueiro e região, e em comparação com as empresas locais, onde serão feitas as análises de atividades profissionais para construir posteriormente o painel inovador. Dentre essas 
é possível destacar a nível nacional as seguintes:

- $\quad$ ELETRISERV - Instalações Elétricas Residenciais e Prediais

Em Lagoa Azul Natal, Rio Grande do Norte, seus serviços residenciais são conversão de tomadas para o novo padrão $(2 \mathrm{P}+\mathrm{T})$; conversão de tomadas de $110 \mathrm{v}$ para $220 \mathrm{v}$; instalação de luminárias, lustres e iluminação embutida no gesso, de ponto de telefone, ponto de luz e acessórios para iluminação, tomada, quadro de luz (quadro de distribuição), ventiladores de teto de todos os modelos, para ar condicionado (tomada, ponto elétrico e disjuntores); manutenção preventiva de instalação elétrica residencial e chuveiros elétricos; aterramento para tomadas; substituição de fusível, disjuntores e interruptores; ligação de energia e luz; distribuição de eletricidade em residências novas; instalação de campainha; e preparação de instalação elétrica para aquecimento e aparelhos em geral.

\section{- $\quad$ Energy Engenharia}

Em 2007 abre, em Itapetininga-SP, a empresa desempenhando os serviços: elaboração de projetos elétricos; constroem toda a infraestrutura necessária para sistemas de distribuição de energia elétrica; manutenção em subestações e equipamentos industriais; inspeção termográfica; análise de carregamento de transformadores e qualidade de energia; parametrização de relés; estudos técnicos de viabilidade e proteção; montagem eletromecânica e manutenção industrial; reforma e manutenção de disjuntores; comissionamento em equipamentos e sistemas elétricos; análise de óleo de transformadores; e eficiência energética destinada a empresas e indústrias de diversos seguimentos.

- $\quad$ DPM Eletricidade Ltda.

Surgi em 1985, no município de Curitiba, Paraná, cuja principal atividade é a prestação de serviços de engenharia consistindo principalmente em: serviços de construção civil e instalações elétricas.

Empresa cuja principal atividade é a prestação de serviços de engenharia consistindo principalmente em: serviços de construção civil, instalações elétricas e hidráulicas e consultoria em engenharia elétrica; e consultoria em engenharia de segurança do trabalho;

Dispõe também de um corpo técnico para que sem custos adicionais, assessor e os clientes na compra e na aplicação de produtos como: disjuntores de média e baixa tensão; painéis, cubículos e CCM; chaves seccionadoras de média e baixa tensão; relés e sistemas de proteção; grupos motores geradores; nobreaks; sistemas de iluminação; sistema de refrigeração; cabos; sistemas de proteção de descargas atmosféricas; barramentos blindados (Bus Way); materiais e equipamentos diversos.

\section{- Tecnoluz}

Fundada em 1989, com sede própria localizada na cidade de Embu das Artes/SP atende toda cidade de São Paulo proporcionando serviços de instalações de cabine primária de 100 a 2000KVA, para-raios (SPDA), entrada de energia padrão individual e coletivo, medição trifásica de energia, controle de reativo banco de capacitores, instalação elétrica de baixa tensão, sistema de iluminação interna e externa, montagem de painéis de comando/distribuição, antenas sistemas VHF/UHF (digital), entrada padrão telefônica $\mathrm{QG}$ e ramais, sistema contra incêndio (SPCI) e manutenção preventiva e corretiva. E fornece materiais elétricos: antenas e acessórios, padrão de entrada de luz/força, chaves/fusíveis, disjuntores, tubos/conexões, cabos, conectores/terminais, automação, botão/sinalizador/contator, timer/rele/inversor, quadros de comando, caixas/quadros de distribuição, interruptores/tomadas, plugues, luminárias, lâmpadas, reatores/transformadores, chuveiros/aquecedores, eletrocalhas/perfilados, para-raios, centrais de alarmes/sensores, ferramentas, centrais de PABX/telefones, postes, ventiladores e estabilizadores/nobreaks.

O nível regional, dentro da cidade de Salgueiro e região também foi pesquisado empresas que atuam em instalações elétricas, fornecendo assim para pesquisa e montagem do painel uma amostra da realidade local do ramo de atuação.

São empresas que em sua maioria fornecem materiais para a construção civil, e 
outras poucas na cidade desenvolvem serviços. Como também a notoriedade no mercado não é bem difundida, praticamente todas não têm sites próprios e atendem apenas na localidade de Salgueiro, não têm filiais fora da cidade.

As empresas que foram entrevistadas que desempenham serviços como instalação e manutenção de ar-condicionado atuam em demais localizações. A empresa AIW Comércio e Serviços, mantém a sede de Juazeiro do Norte-CE que inúmeras vezes sustenta financeiramente a sede em Salgueiro-PE, pois é pouco lucrativa.

As empresas que fornecem materiais em geral para a construção civil foram: Constrular Ferraz Salgueiro LTDA; Agro \& Construção HERCILIO'S; JC Comércio tendo como nome de fantasia Caramurú Tintas; Carua Home Center LTDA APP; Central de Construção; Construacio; e Rocha Material de Construção. As que trabalham com serviços especializados em ar-condicionado são: AIW Comércio e Serviços e Resfriar Climatização. Conserto e atendimento particular de elétricos portáteis: Maria Almir Dantas de Silva tendo como nome de fantasia Capitel. A Capitel nos retratou sobre a falta de mão-de-obra especializada no mercado de Salgueiro, a falta de pessoas que desempenhem essas funções para serem contratada é enorme. A procura pelo serviço também é precária, pois as pessoas muitas vezes não querem consertar aparelhos danificados, optam por comprarem novos e o conserto também é uma dificuldade visto que muitos dos componentes que os compõe são restritos, apenas as empresas que os projetaram detêm seus componentes. A demanda seria grande, pois são muitos os casos de aparelhos danificados por causa de curtos-circuitos, o que derivaria de uma instalação elétrica instável, por diversos motivos. Esse contexto salienta as demandas em termos de erros que podem estar sendo cometidos na execução das instalações elétricas residenciais e comerciais da cidade.

Dentre a atuação no ramo de instalações elétricas destas empresas na cidade de Salgueiro é possível destacar através de questionários de avaliação aplicado as mesmas, uma falta de investimento em equipamentos e inovações bem como a capacitação dos profissionais que atuam na cidade.

Depois de realizada esta pesquisa inicial, o próximo passo foi buscar em visitas em obras de edificações locais dados que pudessem fornecer as atividades no ramo de instalações elétricas, como é executada, se atende aos padrões da norma, e quais possíveis erros pudessem ser identificados para que as atividades que o painel irá agregar atenda a formação do profissional para o mercado de trabalho.

Foram realizadas visitas a edificações residenciais e comerciais da cidade. Um dos exemplos entre as visitas ocorreu na construção de um conjunto de residências unifamiliares composto de uma casa padrão que de acordo com as respostas fornecidas foi garantido que os profissionais que desempenham os serviços elétricos, no caso os eletricistas, todos são formados e tem certificação para tal. Quando questionados sobre se os serviços estavam dentro dos padrões da NBR (Norma Brasileira de Regulamentação) 5410 e se havia tabelas de levantamento de cargas, quadro de distribuição com dispositivos de proteção e se os condutores e eletrodutos foram dimensionados, os profissionais apenas responderam que havia um projeto de instalações elétricas elaborado por um engenheiro (não deixou claro se foi um engenheiro elétrico ou civil) e só começou a ser executado depois de aprovado pelo órgão competente da prefeitura da cidade de Salgueiro. Dentre alguns registros fotográficos da visita podemos destacar:

Figura 1 - Eletrodutos no teto: Visita técnica.

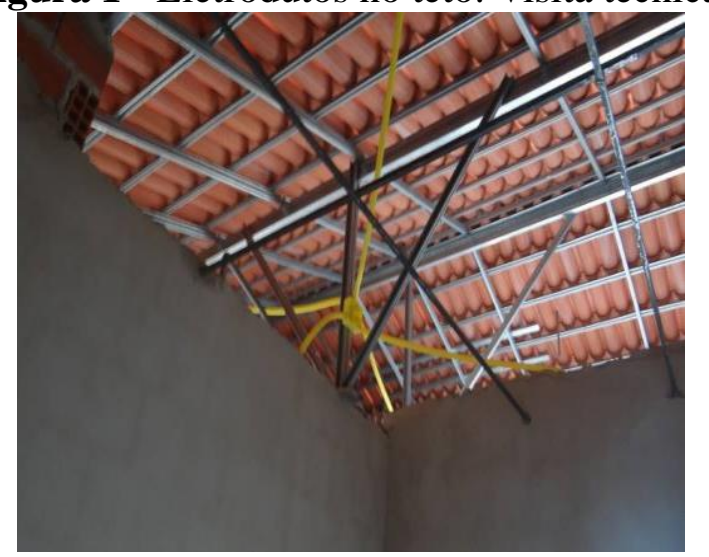

Fonte: Elaborado pelos autores (2016). 
Podem-se observar os eletrodutos da figura 1 não nivelados, conectados por uma caixa de conexão para iluminação, mas observa-se que estão muito soltos e longos caminhos de eletroduto, o que não é aconselhado, pois pela norma, devem ser dimensionados trecho a trecho da instalação, desta forma estão mais passíveis a interferências, fatores externos e eventual rompimento. Agregando assim um fator importante para o uso e montagem do painel para as aulas práticas, a importância da correta instalação dos eletrodutos, visando a segurança e bom uso da instalação.

Figura 2 - Quadro de distribuição finalizado:

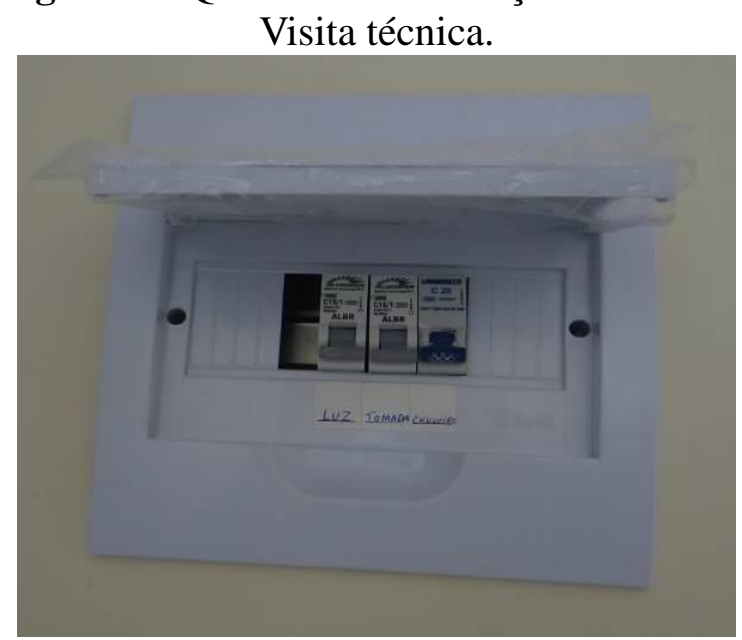

Fonte: Elaborado pelos autores (2016).

Na figura 2, observa-se a separação dos circuitos é importante para segurança das residências, para que não haja eventuais sobrecargas na instalação, principalmente com o chuveiro elétrico que tem um alto consumo de energia elétrica.

Cada circuito terminal está sendo protegido por um disjuntor apropriado para o circuito e com valor de corrente nominal necessária para proteção do mesmo. Desse modo, as divisões dos circuitos terminais correspondem ao mínimo exigido pela norma, pois contém as divisões dos circuitos de iluminação, das Tomadas de Uso Geral (TUG's) e Tomadas de Uso Especifico (TUE's). Todas essas características também serão agregadas ao painel, levando a experiência prática para o aluno em capacitação técnica.
Figura 3 - Instalações de Pontos de Luz Visita técnica.

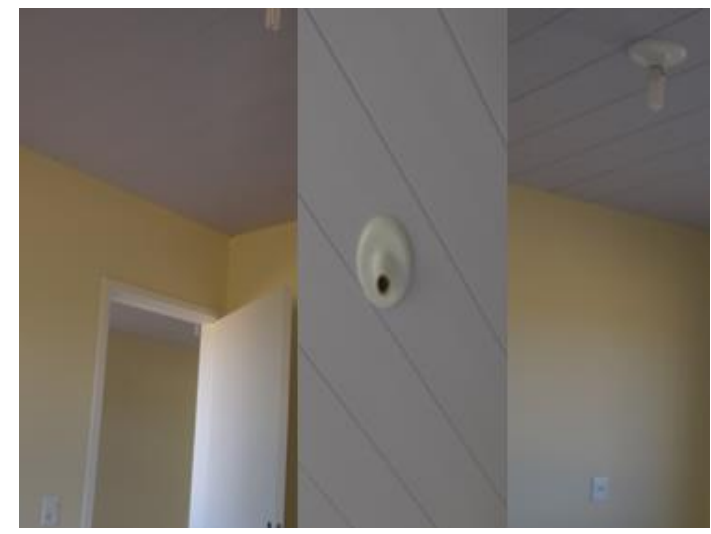

Fonte: Elaborado pelos autores (2016).

A instalação de pontos de luz observada na figura 3 também exprime para as funcionalidades do painel a prática de tais instalações, ligações e conexões, onde os alunos poderão realizar mesma prática em sala de aula com uso do painel, atendendo as normas.

Figura 4 - Instalação de TUG’s na sala: Visita Técnica.

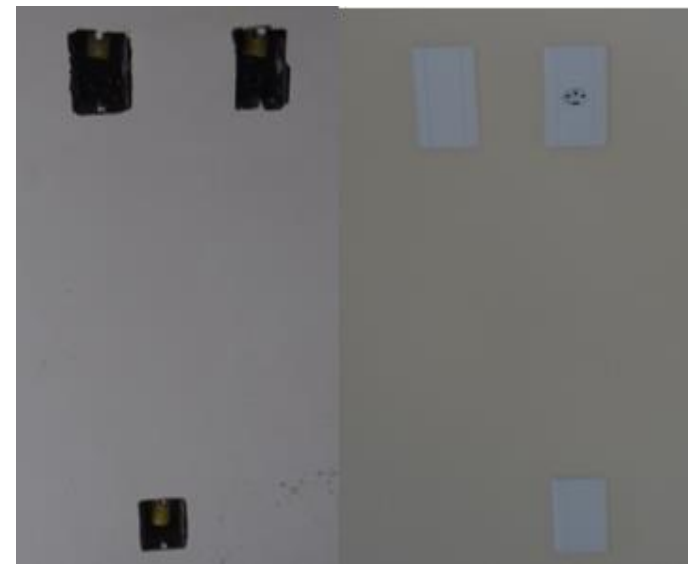

Fonte: Elaborado pelos autores (2016).

As instalações de tugs como observadas na figura 4 (tomadas de uso geral), também são analisadas em sua montagem e ligações, observando a norma 5410, a segurança na colocação das caixas de passagem e fiação. Tais demandas também aplicadas ao painel e uso do aluno.

O painel deverá assim estar de acordo com o recomendado pela norma para a execução de um projeto elétrico. Entre elas os eletrodutos estarem divididos trecho a trecho com caixas de conexão, retilíneos, 
dimensionados e a fiação distribuída dentro deles, sendo atendida sua padronização recomendada de cores, facilitando a manutenção e segurança da instalação. Por tanto, os alunos poderão ficar cientes qual a maneira ideal para ser executada a instalação elétrica com eletrodutos em segurança, e de acordo com padrões diante dos principais erros encontrados nas visitas, a experiência assim será real nas aulas práticas para formação do técnico de acordo com a realidade local.

\section{Resultados e discussões}

Os resultados obtidos consistiram na aquisição dos componentes necessários a montagem do painel e a execução das atividades necessárias a uma instalação com segurança e padronizada de acordo com a NBR 5410. Sendo assim construído o painel que atenda as demandas dos alunos e a capacitação necessária diante das pesquisas realizadas.

Entre os principais componentes adquiridos necessários para fabricação do painel, estão entre os utilizados dentro de uma instalação elétrica usual, entre eles bocais, lâmpadas fluorescentes, interruptores, caixas de passagem, tomadas gerais e específicas como chuveiro elétrico, quadro e disjuntores específicos, quando possível serão adquiridos componentes inovadores que agreguem capacitação nova aos técnicos, como no futuro lâmpadas de led tubulares, entre outras, e quem sabe poder traçar um comparativo de gasto e eficiência em potência entre as lâmpadas. Assim como também aos profissionais que não conhecem na prática os componentes, suas aplicações e montagem, proporcionando a aproximação efetiva com a realidade aplicada e a correção de atividades profissionais de instalações elétricas locais. Dentre estes alguns exemplos estão expostos nas figuras 5,6,7,8,9,10 abaixo:

Figura 5 - Interruptor 3 Seções

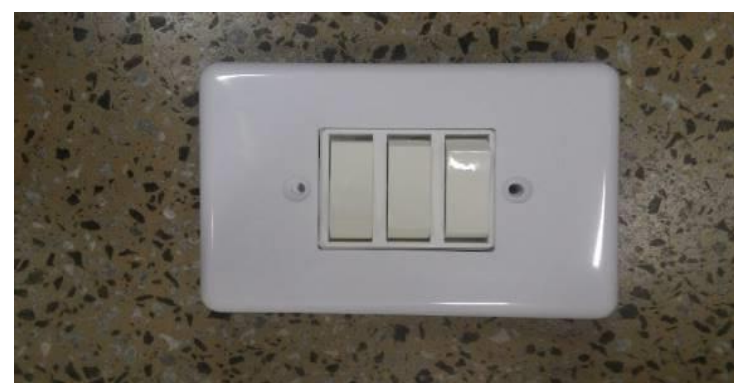

Fonte: Elaborado pelos autores (2016).

Figura 6 - Caixa de Passagem

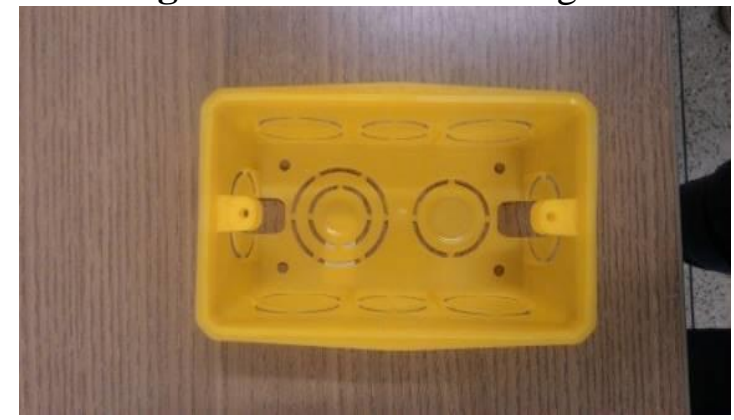

Fonte: Elaborado pelos autores (2016).

Um dos fatores de erro corriqueiramente encontrado em instalações elétricas e na região, é a falta de padronização das cores dos condutores, impossibilitando a manutenção segura sem o conhecimento do condutor correto dentro do circuito, o painel será utilizado e a disposição da montagem pelos alunos com os condutores em cores padronizadas. De acordo com a norma da NBR 5410 o padrão de cores dos fios para as instalações são:

NEUTRO: azul claro.

FASE: amarelo, branco, preto ou vermelho. TERRA: verde

Figura 7 - Lâmpada Fluorescente

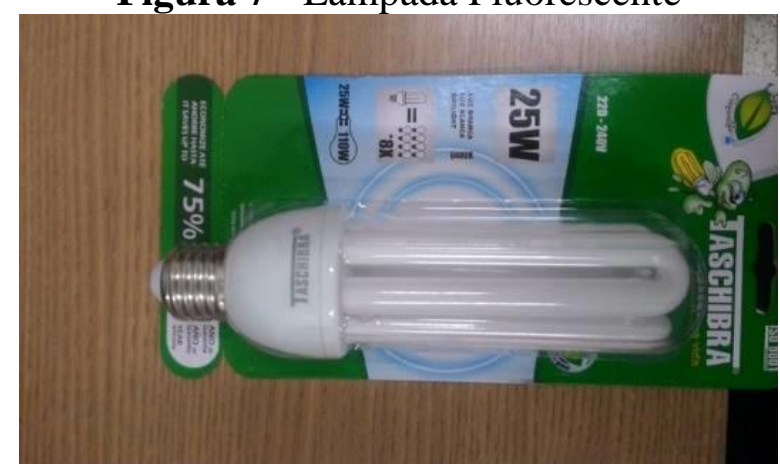

Fonte: Elaborado pelos autores (2016).

Figura 8 - Condutores 


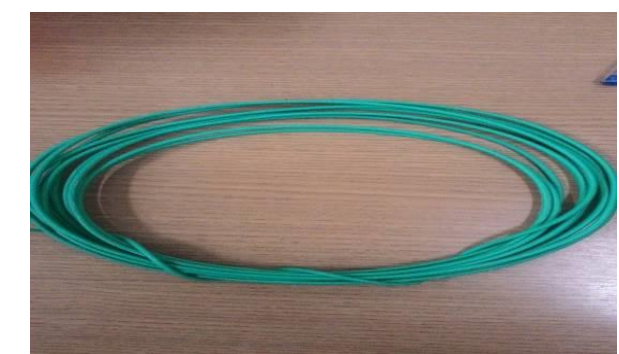

Fonte: Elaborado pelos autores (2016).

Figura 9 - Caixa Octogonal

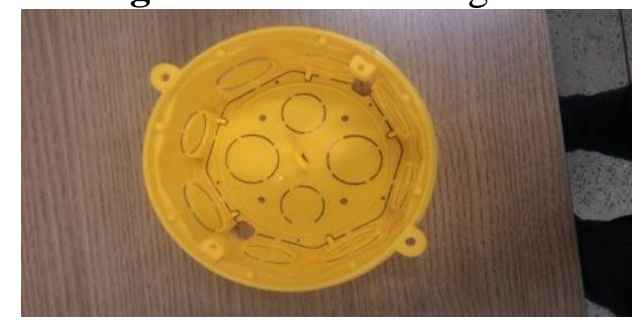

Fonte: Elaborado pelos autores (2016).

Figura 10 - TUG 1 Seção.

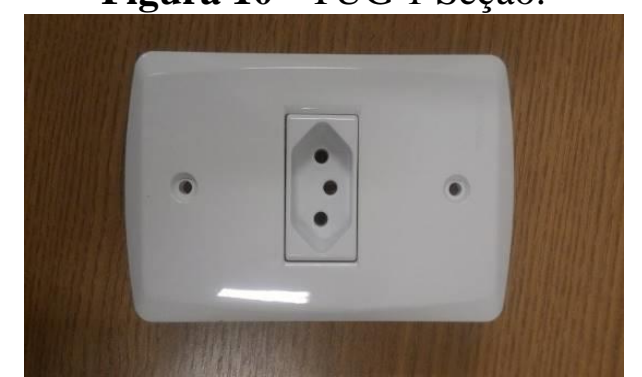

Fonte: Elaborado pelos autores (2016).

Após pesquisa e aquisição dos componentes iniciou-se a montagem do painel em sua estrutura física e análise da alocação dos componentes. O painel foi construído com madeira MDF, após pesquisa de uso e colocação dos componentes chegou-se à conclusão que esse seria a o melhor tipo de material para parte física, otimizando a disposição e montagem das práticas com os alunos. Após a aquisição do MDF foram testadas as opções para inserir os diversos componentes atendendo a variedade de todos e usabilidade do painel, é possível visualiza-lo abaixo na figura $11 \mathrm{em}$ fase de montagem.

Figura 11 - Painel em Fase de Montagem, parte frontal.

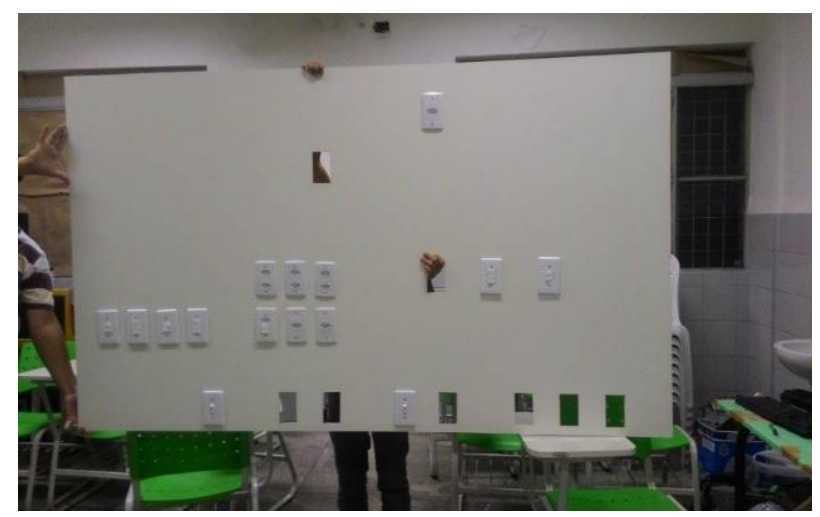

Fonte: Elaborado pelos autores (2016).

Na figura 11 é possível observar a parte frontal do painel contendo os componentes em suas variedade e disposição espaçados e divididos por funcionalidade, tomadas, interruptores, quadro de distribuição e uma tomada específica, o chuveiro elétrico, como exemplo. Já na figura 12 observa-se a parte traseira do painel com demais componentes imprescindíveis em uma instalação elétrica, os eletrodutos, caixas de passagem e todas as conexões onde o aluno poderá realizá-las.

Figura 12 - Parte Traseira do Painel.

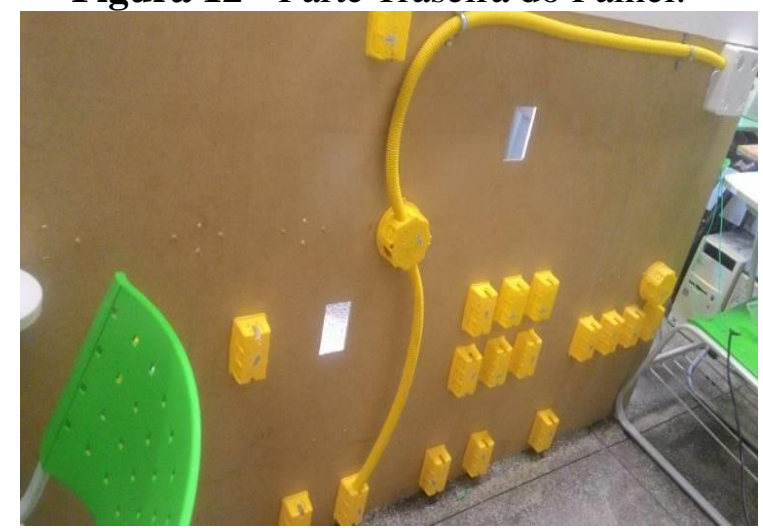

Fonte: Elaborado pelos autores (2016).

A estrutura do painel permite que os alunos tenham acesso a todo alcance e montagem de uma instalação elétrica, na ligação dos condutores dos componentes, no quadro de distribuição, assim como também na parte traseira a realização das conexões entre os eletrodutos e caixas de passagem, auxiliando no processo de aprendizado e prática real, eficaz e dentro das normas para o aluno.

Figura 13 - Conclusão do Painel 


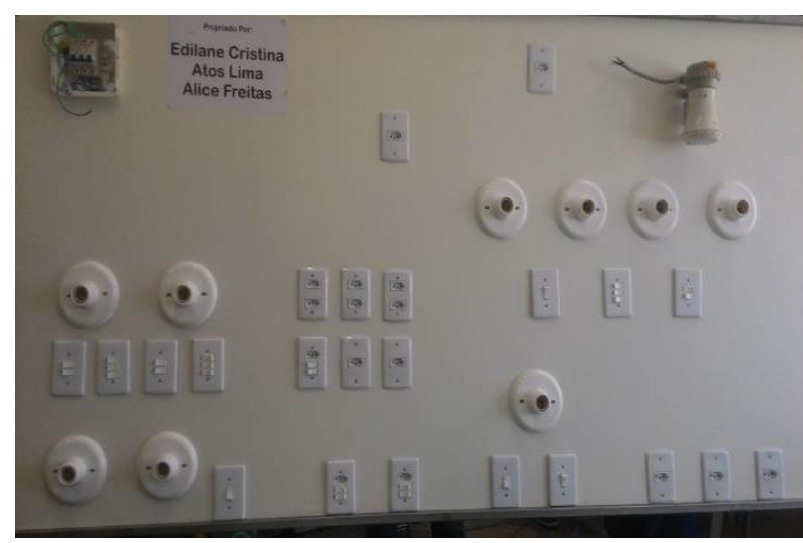

Fonte: Elaborado pelos autores (2016).

- $\quad$ Testes

Foram realizados testes no painel com os estudantes do campus Salgueiro, dos cursos técnicos de informática e o foco da pesquisa, os futuros técnicos de edificações, os quais se apropriarão do aprendizado a fim de propagarem seus conhecimentos no mercado de trabalho nas obras e instalações elétricas locais e regionais. Na figura 14 abaixo, observa-se um aluno interagindo na montagem de um circuito elétrico no painel.

Figura 14 - Testes com alunos

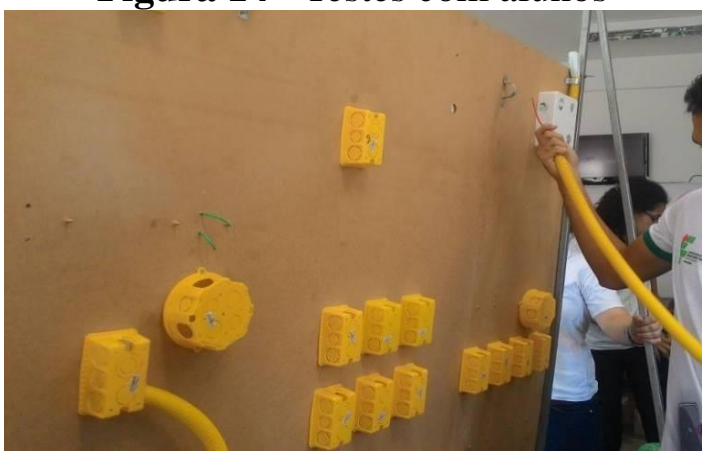

Fonte: Elaborado pelos autores (2016).

Os circuitos montados no painel durantes os testes foram execução básicas das instalações elétricas, como circuitos de iluminação e TUGs, tomadas de uso geral, utilizando-se da NBR 5410, com condutores dimensionais, identificados por suas cores padrões e uso correto dos eletrodutos e caixas de passagem, indicando ao aluno o aprendizado no funcionamento do circuito elétrico e prática normatizada da atividade prática, evitando erros e possíveis futuros riscos dentro da instalação elétricas e de acordo com os encontrados na realidade local, através das pesquisas de campo. Como visto na figura 15.

Figura 15 - Testes com alunos

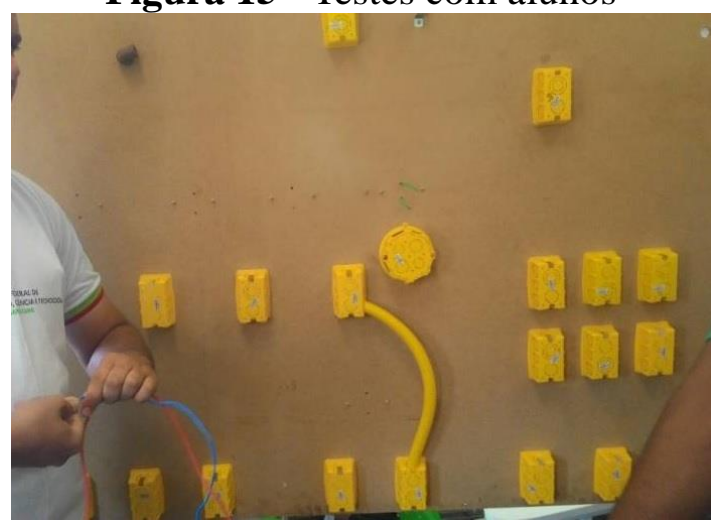

Fonte: Elaborado pelos autores (2016).

- $\quad$ Circuitos de Iluminação

Um dos circuitos testados pelos alunos no painel, é o de iluminação, que de acordo com a NBR deve obedecer que as cargas de iluminação devem ser determinadas como resultado da aplicação da NBR 5413; para os aparelhos fixos de iluminação a descarga, a potência nominal a ser considerada deverá incluir a potência das lâmpadas, as perdas e o fator de potência dos equipamentos auxiliares; em cada cômodo ou dependência de unidades residenciais e nas acomodações de hotéis, motéis e similares deve ser previsto pelo menos um ponto de luz fixo no teto, com potência mínima de $100 \mathrm{VA}$, comandado por interruptor de parede; ( NBR 5410:1997).

Ciente das informações normatizadas, os alunos realizaram a montagem padronizada no painel de um circuito de iluminação com exposto na figura 16, a qual ainda é encontrada instalada de forma errada em algumas edificações, seja pela despadronização das cores dos condutores ou mesmo a utilização dos eletrodutos ou ligações. 
Figura 16 - Circuito de Iluminação

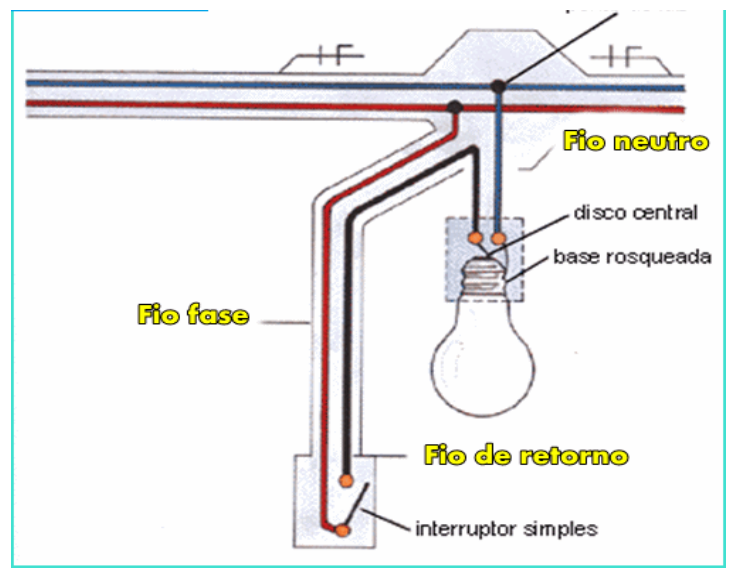

Fonte: (MORENO, 2003)

- Circuitos de TUGs, Tomadas de Uso Geral

Foram testados também pelos estudantes no painel montagens de circuitos de TUGs, onde nas unidades residenciais e nas acomodações de hotéis, motéis e similares, o número de tomadas de uso geral deve ser fixado de acordo com o seguinte: - em banheiros, pelo menos uma tomada junto ao lavatório, desde que observadas as restrições de 9.1; - em cozinhas, copas, copas-cozinhas, áreas de serviço, lavanderias e locais análogos, no mínimo uma tomada para cada $3,5 \mathrm{~m}$, ou fração de perímetro, sendo que, acima de cada bancada com largura igual ou superior a 0,30 $\mathrm{m}$, deve ser prevista pelo menos uma tomada; em halls, corredores, subsolos, garagens, sótãos e varandas, pelo menos uma tomada;( NBR 5410:1997).

Da mesma forma que nos testes com o circuito de iluminação, os alunos realizaram a montagem dos circuitos de TUGs, obedecendo as NRs, em todos os seus padrões. O circuito das TUGs segue exposto na figura 17 abaixo.

Figura 17 - Circuito de Tomadas

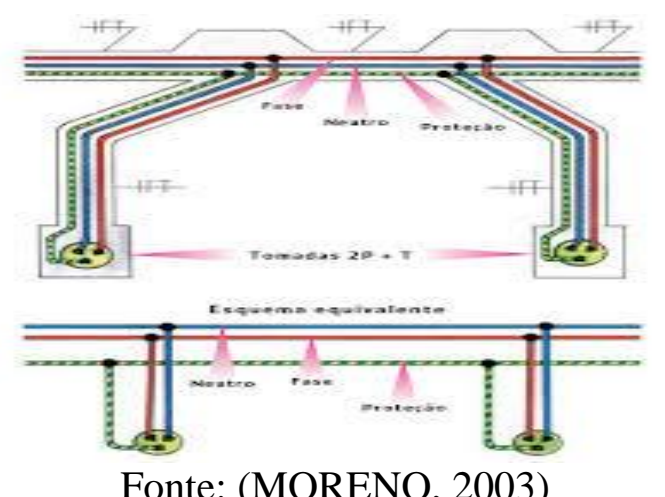

- Circuitos de TUEs, Tomadas de Uso Específico.

As tomadas de uso específico devem ser atribuídas uma potência igual à potência nominal do equipamento a ser alimentado; quando não for conhecida a potência nominal do equipamento a ser alimentado, deve-se atribuir à tomada de corrente uma potência igual à potência nominal do equipamento mais potente com possibilidade de ser ligado, ou a potência determinada a partir da corrente nominal da tomada e da tensão do respectivo circuito; as tomadas de uso específico devem ser instaladas, no máximo, a $1,5 \mathrm{~m}$ do local previsto para o equipamento a ser alimentado.

Os alunos fizeram os testes utilizando um chuveiro elétrico que consta no painel a disposição para a execução e aprendizado da ligação da tomada específica, também de acordo com as NRs, o circuito pode ser observado na figura 18 abaixo.

Figura 18. Circuito de Tomadas Específicas

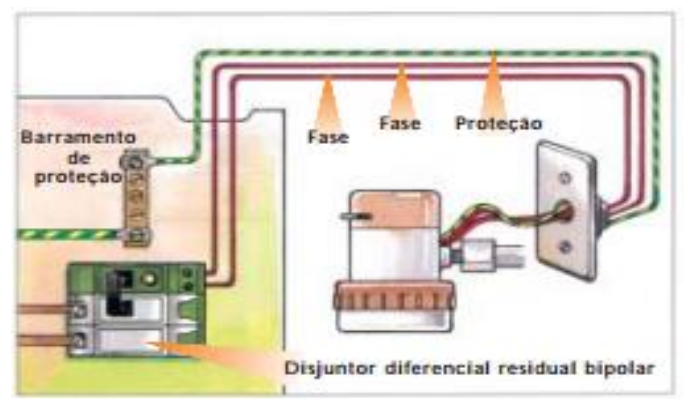

Fonte: (MORENO, 2003)

Como resultado avaliativo das pesquisas realizadas e construção do painel, bem como os testes executados pelos alunos, foi realizado um questionário qualiquantitativo com os alunos 
após os testes de montagens dos circuitos no painel. O questionário está exposto na figura 19 abaixo:

Figura 19. Questionário aplicado aos alunos que realizaram testes no painel.

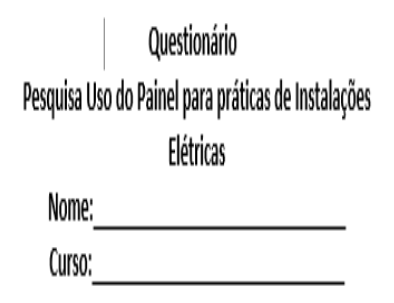

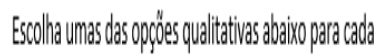
item analisado da pescuiss sobres slas impressobes en

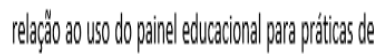
instalecoes eletricicas.

\section{O que achou do visual do painel em reagço a} identificer os componenteses utillzados em una instadecoedeletica?

() Excelente

U. Bom

() Regular

U. Wrim

U.Jésimo

\section{0 painel atende conter os componentes}

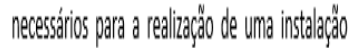
eléticice?

\section{(I)Excelente}

(J)Bom

ULRegular

U., Ruim

U.Jessimo
6. Em qual nivel vocé acha que o uss do painel nas aulas de instabçoes eletricas pode methorar 0 aprendizado dad discipina,

(1) Excentente

U. Bom

LLRegular

U.Juim

UPersimo

\section{Em oual nivel você acredita que a usilizaccóo do}

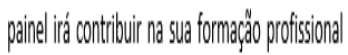

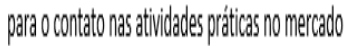
detraballo,

()Eccelente

(LBom

LLRegular

U.) Ruim

(Jéssimo

\section{Em oual nivel vocé acredita que a unilizaço do} paninel iríá contibuir na formagco de um

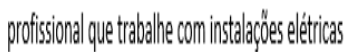
de scordc com as nommas dentro do mercado de trabalho, (|)Excentente ULBOM U.Jegevalar U. Ruim

\section{O que vocé achou da disposiçä (local e espacoco) dos componenteres nopainel? U. Excelente \\ U. Bom \\ Luegeglar \\ U. Ruim \\ UPéssimo}

4. O painel atende as necessidades en realizar

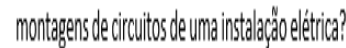

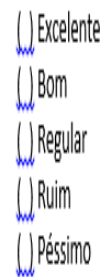

5. Como vocé classificoria a experiência de alla prática de montagen de circuitos de instabçoles eléticics nopainel,

U. Exxelente

U. Bom

ULegevar

U. Kuim

U.Jésimo
9. Em qual nivel vocé acredita que a uitiliaço do painel poderá corrigit erros na execugáo de

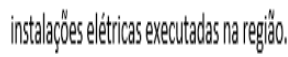
U. Excelente I. Bom U.Jegevar L. Ruim UPersimo

10. Caso deseje por favor explicar o porguê de aguns dositens saima.

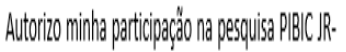
Pessuiss de Montrgegen de Painel de Instabçes Eletiticas 2015-2016

ASS.

Fonte: Elaborado pelos autores (2016).

Os resultados obtidos expressaram um faixa de mais de 95\% dos alunos satisfeitos com o painel seu uso, sua estrutura física e como ele proporcionar uma experiência mais completa em relação a prática de em instalações elétricas e seus circuitos básicos, podendo agregar novas funcionalidades ou inovações ainda não encontradas na realidade local e que constam em cenário nacional.

Os alunos egressos poderão assim contribuir com a comunidade oferecendo uma formação mais sólida na atuação das instalações elétricas locais dentro do mercado de trabalho, oferecendo práticas profissionais de acordo com as normas vigentes e melhor execução dos projetos com segurança e usabilidade. 


\section{Conclusões}

A conclusão deste projeto de pesquisa foi a finalização da construção e montagem do painel educacional inovador, que será utilizado para as aulas práticas de instalações elétricas no campus Salgueiro. O painel se caracteriza de forma diferente aos encontrados no mercado devido a suas características específicas baseadas na pesquisa, erros encontrados em instalações elétricas locais, e de profissionais que atuam na região, capacitando-os assim para interagir com o meio em que vivem, e utilizando um equipamento prático voltado para isso.

Foram feitas análises realizadas nas plataformas virtuais, nas pesquisas de empresas no ramo de instalações elétricas do Brasil, bem como nos questionários e levantamento de dados realizados nas empresas de instalações elétricas da cidade de Salgueiro e região.

Também foram levantados dados de pesquisas de campo, baseadas nas visitas realizadas as instalações elétricas da cidade de Salgueiro e região, onde foram observadas, as falhas, as boas práticas, a atuação profissional, o projeto dentro dos padrões da norma, concluindo assim um conjunto de análises que nos põe em situação de uma possível construção do painel com todos os dados, visitas, pesquisas, registros fotográficos e análises adquiridas.

Todos estes dados agregaram dados sobre componentes e instalações elétricas assim como a importância de equipamentos modernos, seguros, utilizados em projetos de instalações elétricas, sérios e responsáveis, baseando-se no trabalho de profissionais capacitados na área bem como nas normatizações existentes. Todas as informações obtidas são norteadoras para que fosse atingindo os objetivos na constituição do painel, que finalizado fornece, segundo pesquisa realizada entre os usuários, um suporte satisfatório para aulas práticas que auxiliarão na formação do técnico de edificações egresso do IF Sertão-PE campus Salgueiro que atuará diretamente nesta área na região, contribuindo de forma inovadora, técnica e responsável.

\section{Referências}

ABNT, ABNT NBR. 5410: 2004-Instalações elétricas de baixa tensão. 2004.

ELEFIO - CABOS ELÉTRICOS. Disponível em <http://www.elefio.com.br/>. Acesso em: 20 maio 2014.

INSTITUTO FEDERAL DE EDUCAÇÃO, CIÊNCIA E TECNOLOGIA DO SERTÃO PENAMBUCANO - CAMPUS SALGUEIRO. COORDENAÇÃO DE EDIFICAÇÕES. Projeto pedagógico do curso - Técnico de nível médio integrado em Edificações. Disponível em: $\quad<$ http://www.ifsertaope.edu.br/reitoria/images/cursos/mediointegrado/ppc\%20curso $\% 20 \mathrm{de} \% 20$ edificaes $\% 2$ 0mdio\%20integardo\%20-

\%20campus\%20algueiro.pdf $>$. Acesso em: 24 maio 2014.

LIGHT ENGENHARIA.Disponível em: <http://www.lightengenharia.com.br/Servi\%E7 os.htm. Acesso em: 24 maio 2014.

MORENO, H. Instalações Elétricas Residenciais. Elektro/Pirelli. 2003.

TIGRE. Disponível em: $<$ http://www.tigre.com.br/pt/sistemas.php?rcr_i $\mathrm{d}=5 \& \mathrm{cpr} \mathrm{id}=12 \& \mathrm{cpr}$ id pai $=4>$. Acesso em: 20 maio 2014. 